\title{
Evolution of maternal provisioning in ophiuroid echinoderms: characterisation of egg composition in planktotrophic and lecithotrophic developers
}

\author{
Inke Falkner ${ }^{1}$, Mary A. Sewell ${ }^{2}$, Maria Byrne ${ }^{3, *}$ \\ ${ }^{1}$ Bosch Institute, School of Medical Sciences, University of Sydney, Sydney, NSW 2006, Australia \\ ${ }^{2}$ School of Biological Sciences, University of Auckland, Auckland 1010, New Zealand \\ ${ }^{3}$ Schools of Medical and Biological Sciences, University of Sydney, Sydney, NSW 2006, Australia
}

ABSTRACT: For free-spawning marine invertebrates, the egg is the unit of maternal investment in offspring. For many taxa, there is a major life-history trade-off between production of many small, nutrient-poor eggs in high-fecundity species and fewer large, nutrient-rich eggs in low-fecundity species. In echinoderms, the switch from small eggs in species with ancestral-type feeding larvae to large eggs and non-feeding larvae is a significant change with major consequences for larval ecology and juvenile success. In this first comparative study of maternal investment in the Ophiuroidea across species with a range of egg sizes and larval types, the egg protein and lipid content of 4 species with planktotrophic and 6 species with lecithotrophic larvae were characterised. The planktotrophs produced eggs dominated by protein with triacylglycerol as the main energy storage lipid. The switch to lecithotrophy in the Ophiuroidea is associated with an increase in energy storage lipids to produce an energy-dense egg, as is typical of echinoderms with this mode of development. The eggs of the lecithotrophs, however, contained several novel lipid classes not found in ancestral-type ophiuroid eggs. These eggs also differed from those of other echinoderms with lecithotrophic development in the presence of these novel lipids rather than up-scaling of the ancestral maternal provisioning strategy. Our findings support the hypothesis of independent evolution of lecithotrophy multiple times in the Echinodermata. In the Ophiuroidea, this is seen in the evolution of different lipid provisioning patterns between species with large eggs.

KEY WORDS: Maternal investment - Evolution . Marine invertebrates · Echinodermata · Ophiuroidea

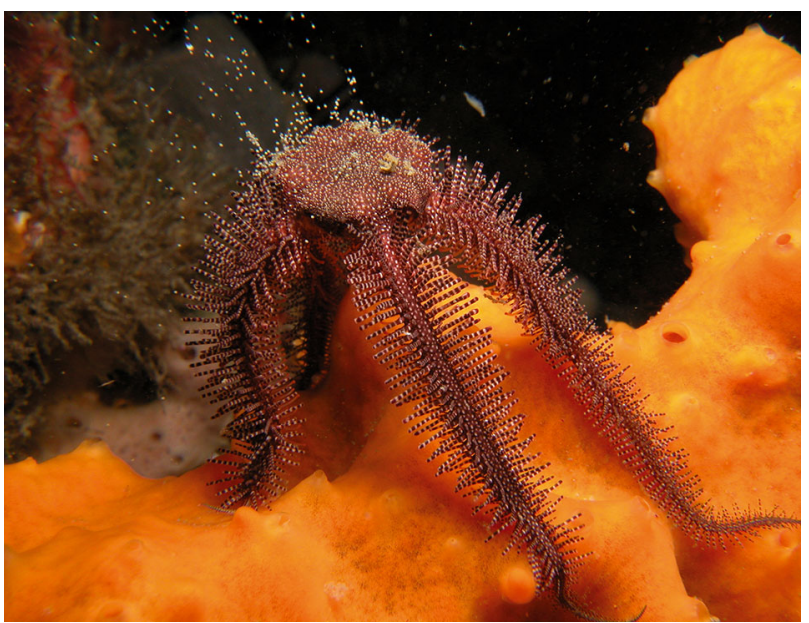

A female Clarkcoma pulchra spawning eggs. This species has a lecithotrophic larva.

Photo: David Hariasti, www.daveharasti.com

\section{INTRODUCTION}

For free-spawning marine invertebrates, the egg is the unit of maternal investment in offspring (Thorson 1950). For many taxa, there is a major life-history trade off between production of many small, nutrient-poor eggs in high-fecundity species with feeding larvae and production of fewer large, nutrient-rich eggs in low-fecundity species with non-feeding larvae, although facultative feeding larvae are being discovered (e.g. Thorson 1950, Vance 1973, Emlet 1986, Emlet et al. 1987, Jaeckle 1995, McEdward \& Miner 2001, Villinski et al. 2002, Falkner et al. 2006, Allen \& Pernet 2007, Moran \& McAlister 2009, Moran et al. 2013). 
The egg supplies a wide range of structural and nutritional materials for developing embryos and larvae. Within taxonomic groups, small eggs are dominated by protein, whereas large eggs have enhanced lipid stores. This difference is reflected in egg buoyancy, with small eggs usually being negatively buoyant, while the presence of extensive lipid inclusions in large eggs increases their buoyancy (Emlet et al. 1987, Emlet 1994, Jaeckle 1995, Byrne et al. 1999). There may be selection for eggs of different buoyancy with respect to where fertilization occurs and larval dispersal strategy (Emlet et al. 1987, Emlet 1994). Egg size evolution is also influenced by species' fertilization ecology, where increased egg size facilitates fertilization in sperm limitation conditions, the 'egg target model' (Levitan 1993). In some cases, increased egg size is accomplished by increased egg water content, rather than nutrient levels (Moran et al. 2013). Clearly, many selective forces have influenced the size and nutritive composition of marine invertebrate eggs.

The best comparative data on egg nutritive profiles and evolution of development are from asteroid and echinoid echinoderms (Jaeckle 1995, Moran \& McAlister 2009, Moran et al. 2013). A feeding planktotrophic larva is considered the ancestral state for the Echinodermata (Strathmann 1978, Raff \& Byrne 2006), with an increase in maternal investment being a crucial step in the switch to non-feeding lecithotrophic development (Strathmann 1978, 1993, Wray 1996, Raff \& Byrne 2006). The evolution of lecithotrophic larvae is an ecologically significant transformation that has occurred multiple times independently within each echinoderm clade (Strathmann 1978, Wray 1996, Raff \& Byrne 2006). Data from asteroid and echinoid eggs shows that energy content does not scale with egg volume. Energy concentration is higher in the large eggs of species with lecithotrophic development due to increased lipid reserves, particularly energy storage lipids (Jaeckle 1995, Byrne et al. 1999, McEdward \& Morgan 2001, Villinski et al. 2002, Prowse et al. 2009, Whitehill \& Moran 2012, Moran et al. 2013). In addition, many of the lipid reserves deposited in the eggs of echinoderms with lecithotrophic development are not used for the pelagic life phase. These lipids are instead stored for the juvenile, likely due to selection for enhanced juvenile performance (Emlet \& HoeghGuldberg 1997, Prowse et al. 2008, 2009).

In echinoderms, egg size is generally a good indicator of developmental mode (Emlet et al. 1987, Jaeckle 1995, Sewell \& Young 1997). Species producing small eggs (<150 to $250 \mu$ m diameter) have larvae that depend on exogenous resources to reach the juvenile stage, while those with large eggs ( $>250$ to $300 \mu \mathrm{m}$ diameter) develop to metamorphosis without feeding (Strathmann 1985, Emlet et al. 1987, Jaeckle 1995). Identification of a few echinoderm species with facultative planktotrophy which have eggs intermediate in size and which can avail themselves of exogenous food, but do not need to feed to achieve the juvenile stage, provides insights into the transition to lecithotrophy (Emlet 1986, Hart 1996, Wray 1996, Allen \& Pernet 2007, Allen \& Podolsky 2007). This transition appears to have occurred through a facultative feeding larva, a larval form that might not be evolutionarily stable (Wray 1996).

A distinct bimodality in egg size distribution and development mode is characteristic of echinoids, asteroids and holothuroids (Sewell \& Young 1997). However, many ophiuroids with lecithotrophic development have small eggs ( 200 to $300 \mu$ m diameter), similar in size to those of other echinoderms with planktotrophic development (Byrne 1991, Sewell \& Young 1997, Selvakumaraswamy \& Byrne 2000a,b, 2004, Falkner et al. 2006, 2013). One species with a $230 \mu \mathrm{m}$ diameter egg has a facultative feeding larva (Allen \& Podolsky 2007). The comparatively small eggs of many ophiuroids with lecithotrophic development are suggested to reflect the lower size range that can support this mode of development (Falkner et al. 2006), as also noted for crinoids which have small eggs (<250 to $300 \mu \mathrm{m}$ diameter) (McEdward et al. 1988).

The pattern of maternal provisioning in ophiuroids may differ energetically from that of other echinoderms (Sewell \& Young 1997). Maternal investment, however, is not well documented for this class of echinoderms, despite their abundance and ecological importance. A recent study indicated that the small eggs of an ophiuroid with planktotrophic development had comparatively higher protein levels and lower lipid levels compared with similarly sized echinoid eggs (Whitehill \& Moran 2012). Here, in this comparative study of maternal investment in the Ophiuroidea, the egg composition of 10 species was investigated with a focus on lipid provisioning. The ophiuroids investigated included 4 species (Ophionereis fasciata, Ophiopteris antipodum, Ophiocoma dentata and Ophiactis resiliens) with small eggs (71 to $110 \mu \mathrm{m}$ diameter) and planktotrophic development and 6 species (Ophionereis schayeri, Ophiarachnella ramsayi, Ophiocoma endeani, Ophiarthrum elegans, Clarkcoma pulchra and Clarkcoma canaliculata) with large eggs (248 to $381 \mu \mathrm{m}$ ) and lecithotrophic development. Total lipid and protein content as well 
as lipid class were documented on a per egg basis, as in other recent studies of echinoderm eggs (Sewell 2005, Falkner et al. 2006, Byrne et al. 2008, Prowse et al. 2008, McAlister \& Moran 2012, 2013). The species included closely related congeners with contrasting modes of development. In the genus Ophionereis, $O$. fasciata appears to be the only species known to have planktotrophic development, while $O$. schayeri has lecithotrophic development (Selvakumaraswamy \& Byrne 2000b, 2004). In the genus Ophiocoma, O. dentata has small eggs and planktotrophic development, while $O$. endeani is the only Ophiocoma species known to have large eggs and lecithotrophic development.

The data generated from the eggs of 10 species were used to address 4 hypotheses: (1) The large eggs of ophiuroids with lecithotrophic development differ in lipid and protein content from the small eggs of species with planktotrophic development, indicating that the shift to lecithotrophy was associated with a change in maternal provisioning; (2) The ancestral life history with a small egg and a feeding larva is associated with a similar pattern of maternal provisioning across the Ophiuroidea; (3) The independent evolution of lecithotrophy multiple times within the Ophiuroidea led to the evolution of different maternal provisioning between species with large eggs; (4) Ophiuroids with lecithotrophic development with small eggs ( 250 to $300 \mu \mathrm{m}$ diameter) have a different maternal provisioning strategy with respect to lipid and protein content compared to those of ophiuroids and other echinoderms with larger eggs with $>300 \mu \mathrm{m}$ diameter. To assess how the nutrient profiles of ophiuroid eggs compare with those determined for other echinoderms, the linear relationships determined for egg protein and lipid content and egg volume (Jaeckle 1995, Sewell \& Manahan 2001, Moran et al. 2013) are revisited here with the addition of the ophiuroid data.

\section{MATERIALS AND METHODS}

\section{Collection}

Mature ophiuroids were collected from locations in Australia and New Zealand (Table 1). With the exception of Ophiarachnella ramsayi, Ophiocoma endeani and Ophiarthrum elegans, spawning was either spontaneous after collection or was induced using heat and light shock (Selvakumaraswamy \& Byrne 2000a). The eggs of most species were obtained from 2 to 3 independent spawning events, each involving at least 3 females (Table 1). Clarkcoma canaliculata was only spawned once. For the 3 species that could not be induced to spawn, fullygrown eggs were dissected out of the gonads of 3 females for each species. Spawned and dissected eggs were washed 3 times with $1 \mu \mathrm{m}$ filtered sea water (FSW). Egg diameters ( $\mathrm{n}=30$ per species) were measured on freshly spawned eggs using an ocular micrometer. Spawned eggs of ophiuroids are round and so diameter is a good metric to use to calculate volume using the formula $v=4 / 3 \pi \times r^{3}$ (Table 1 ).

\section{Lipid and protein analysis}

For lipid analyses, 3 egg samples (planktotrophs: 500 to 600 eggs, lecithotrophs 10 to 40 eggs) from each spawning/dissection were placed in $1.5 \mathrm{ml}$ tubes on ice and briefly centrifuged, and the seawater was

Table 1. Species sampled with their mode of development, mean egg diameter \pm SE, mean egg volume calculated from average egg diameter, buoyancy, and collection details. n: number of spawnings/dissections; P: planktotrophic developer; L: lecithotrophic developer

\begin{tabular}{|c|c|c|c|c|c|c|c|c|}
\hline Taxon & $\begin{array}{l}\text { Species } \\
\text { code }\end{array}$ & Mode & $\mathrm{n}$ & $\begin{array}{l}\text { Egg diam. } \\
\qquad(\mu \mathrm{m})\end{array}$ & $\underset{\text { (nl) }}{\text { Egg vol. }}$ & Buoyancy & Collection time & Location \\
\hline \multicolumn{9}{|l|}{ Ophionereididae } \\
\hline Ophionereis fasciata & OF & $\mathrm{P}$ & 3 & $103 \pm 0.4$ & 0.57 & Neg. & Feb 2004/2005 & Leigh, NZ \\
\hline Ophionereis schayeri & OS & $\mathrm{L}$ & 3 & $248 \pm 1.4$ & 7.94 & Neg. & Dec-Apr 2004/2005/2008 & Sydney, AUS \\
\hline \multicolumn{9}{|l|}{ Ophiocomidae } \\
\hline Ophiocoma dentata & OD & $\mathrm{P}$ & 3 & $71 \pm 0.7$ & 0.19 & Neg. & Nov 2004 & One Tree Island, AUS \\
\hline Ophiocoma endeani & OE & $\mathrm{L}$ & 3 & $353 \pm 2.0$ & 23.03 & Pos. & Mar/Apr 2004/2005/2008 & Coffs Harbour, AUS \\
\hline Clarkcoma canaliculata & $\mathrm{CC}$ & $\mathrm{L}$ & 1 & $266 \pm 2.6$ & 9.85 & Neg. & May 2004/2005/2008 & Sydney, AUS \\
\hline Clarkcoma pulchra & $\mathrm{CP}$ & $\mathrm{L}$ & 3 & $290 \pm 3.4$ & 12.77 & Neq. & May $2004 / 2005 / 2008$ & Sydney, AUS \\
\hline Ophiarthrum elegans & OAE & $\mathrm{L}$ & 2 & $381 \pm 4.0$ & 28.96 & Pos. & Nov 2004 & One Tree Island, AUS \\
\hline Ophiopteris antipodum & $\mathrm{OA}$ & $\mathrm{P}$ & 2 & $110 \pm 0.7$ & 0.69 & Neg. & Feb 2004/Apr 2005 & Leigh, NZ \\
\hline \multicolumn{9}{|l|}{ Ophiactidae } \\
\hline Ophiactis resiliens & OAR & $\mathrm{P}$ & 3 & $83 \pm 0.3$ & 0.27 & Neg. & June/July 2006 & Sydney, AUS \\
\hline \multicolumn{9}{|l|}{ Ophiodermatidae } \\
\hline Ophiarachnella ramsayi & OR & $\mathrm{L}$ & 2 & $342 \pm 4.0$ & 20.94 & Pos. & Dec-Apr 2004/2005/2008 & Sydney, AUS \\
\hline
\end{tabular}


removed. The samples were stored at $-80^{\circ} \mathrm{C}$. For protein analyses, 2 samples (planktotrophs: 2000 to 3000, lecithotrophs: 60 to 250) from each spawning/ dissection were collected and also frozen at $-80^{\circ} \mathrm{C}$. For the planktotrophs, the number of eggs in $100 \mu \mathrm{l}$ aliquots of an egg suspension were counted to determine the volume of suspension required. The large eggs of lecithotrophs were counted individually for the lipid and protein analyses.

Lipid was extracted from frozen egg samples following Sewell (2005) with minor modifications. Ketone was used as internal standard for the egg lipid extracts of planktotrophs because natural concentrations of this lipid are low in marine tissues (Parrish \& Ackman 1983, Sewell 2005). The eggs of the lecithotrophs contained wax and methyl esters, which overlapped with ketone in the 3-step development system used (see below). As a result, cetyl alcohol and aliphatic hydrocarbon were used as the internal standard for analyses of these eggs. The lipid extracts were analysed immediately or stored at $-20^{\circ} \mathrm{C}$ for 2 to $3 \mathrm{~h}$ prior to analysis. Shortly before analysis, the lipid extracts were dried in a light stream of $\mathrm{N}_{2}$ gas and re-dissolved in 10 to $20 \mu \mathrm{l}$ chloroform.

Egg lipid classes were determined and quantified using the Iatroscan® Mark $\mathrm{V}^{\text {new }}$ thin layer chromatography and flame ionization detection system (TLCFID) system. A 3-step development by Parrish (1987) was used in the first analysis to achieve best separation of all lipid classes. Development solutions and times followed Sewell (2005) with minor modification. To separate triacylglycerol (TAG) and diacylglycerol ether (DAGE), a separate analysis of lipid extracts was made using a single development for $40 \mathrm{~min}$ in a non-polar solvent system of hexanediethyl ether (96:4 v/v) (Prowse et al. 2009). Peak identification was confirmed by spiking with known lipid standards.

Individual lipid classes were quantified by producing calibration curves for each class based on commercially available lipid standards, with the exception of the custom-made squalene standard for DAGE provided by Dr P. Nichols (CSIRO) and Dr P. Virtue (University of Tasmania). Three replicate samples for each spawning or dissection were analysed for each species. Lipid composition for each replicate was determined by spotting twice in the same run on 2 chromarods. The average of these 2 runs for each lipid class was used for data analysis. The amount of energy storage lipids was calculated by adding the amount of aliphatic hydrocarbon $(\mathrm{AH})$, wax ester (WE), methyl ester (ME) and triacylglycerol + diacylglycerol ether (TAG + DAGE). The amount of struc- tural lipids was calculated by adding the amount of sterol (ST), acetone-mobile polar lipids (AMPL) and phospholipid (PL). The total lipid content in each egg sample was calculated from the energy and structural lipids. With the exception of C. canaliculata (spawned once), the overall mean for each species was calculated by averaging the values for all spawnings/ dissections.

For protein content, 2 samples from each of the spawnings/dissections were extracted and analysed. Egg samples were thawed on ice, and $100 \mu \mathrm{l}$ of cooled lysis buffer (20 mM Tris- $\mathrm{HCl}, 130 \mathrm{mM} \mathrm{NaCl}$, $5 \mathrm{mM}$ EDTA and $1 \%$ TritonX-100) and $1 \%$ protease inhibitor cocktail (Sigma) was added. The eggs were homogenized with a probe sonicator, incubated on ice for $15 \mathrm{~min}$ while being shaken and then centrifuged at $18900 \times g$ for $20 \mathrm{~min}$ at $4^{\circ} \mathrm{C}$. The supernatant of eggs from lecithotrophs was covered with a lipid layer; therefore, these samples were transferred to a clean $1.5 \mathrm{ml}$ Eppendorf and centrifuged again to ensure all lipid was removed. The extracted protein was stored at $-80^{\circ} \mathrm{C}$ for subsequent analysis.

Total protein was quantified using the Micro BCATM protein assay kit (Pierce) following the manufacturer's instructions. Protein samples were diluted in deionized water (1:50 or 1:100), and each sample was measured twice. For analysis, $100 \mu \mathrm{l}$ of diluted sample was pipetted into a microplate well to which $100 \mu \mathrm{l}$ of the working solution (Micro BCA Reagent A, B and C) were added. Absorbance was measured at $550 \mathrm{~nm}$ using a Bio-Rad plate reader. A standard curve was prepared by plotting the average, blankcorrected reading for each BSA standard with its concentration in $\mu \mathrm{g} \mathrm{ml} \mathrm{m}^{-1}$. This standard curve was used to determine the total protein concentration. The mean for the 2 measurements was used to calculate the protein content.

\section{Data analyses}

Egg lipid data for the 10 species were divided by egg volume $(\mathrm{nl})$. The data were classified in 2 categories for comparison: energy storage and structural lipids. Standardised energy storage, structural lipid and protein data were used for a priori or planned contrasts. These data were analysed by 1-way analysis of variance (ANOVA) (NCSS 2001) with species as a fixed factor and spawning event/dissection as a nested factor to determine which egg nutrient components were associated with the switch to nonfeeding development. In contrast to other studies on echinoderms, we cannot use 'female' as the nested 
factor because female ophiuroids cannot be induced to spawn in isolation (Selvakumaraswamy \& Byrne 2000b). Hence, each spawning event may represent the eggs from $>1$ female. Prior to the ANOVA, the assumption of homogeneity of variances was examined by plotting the residuals against predicted values (group means). The data were ln-transformed where necessary to achieve homogeneity of variance.

To further assess whether the small and large eggs differed in lipid and protein content, all species, except $C$. canaliculata for which we only had 1 spawning event, were compared by non-parametric multivariate analysis based on standardized Euclidean distances (Primer v. 6, Plymouth Marine Laboratories). Means of all lipid classes (ng) and total protein (ng) standardised by egg volume (nl) were used for permutational multivariate analysis of variance (PERMANOVA, Primer v. 6). This multivariate analysis was used to test the hypothesis that the difference in lipid and protein profiles was greater between the eggs of planktotrophs and lecithotrophs than within each group. In this analysis, development mode was a fixed factor, and species was a random factor. The multivariate data were visualised by non-metric multidimensional scaling (nMDS) using Primer (v. 6). Dispersion of the lipid class and protein data was analysed by permutational analysis of multivariate dispersions (PERMDISP, Primer v. 6) using the distances to centroids.

The relationships determined for egg protein and lipid content and egg volume in echinoderm eggs (Jaeckle 1995, Sewell \& Manahan 2001, Moran et al. 2013) are revisited here with the addition of the ophiuroid data (see Table S1 in the Supplement at www.int-res.com/articles/suppl/m525p001_supp.pdf). These data were analysed by linear regression.

\section{RESULTS}

\section{Lipid profiles}

Five lipid classes were identified in the eggs of the 4 species with planktotrophic development using the triple development method (Table S1 in the Supplement, Fig. 1). These classes included the structural lipids sterol (ST), acetone-mobile polar lipids (AMPL) and phospholipid (PL) and the energy storage lipids aliphatic hydrocarbon (AH) and triacylglycerol (TAG) (Table S1, Fig. 1). In these eggs, TAG was the major energy storage lipid, ranging from 28 to $48 \%$ of total lipid, while phospholipid was the most abundant structural lipid, composing 35 to $43 \%$ of total lipid (Table S1, Fig. 1). The single step non-polar method indicated that these eggs did not contain detectable levels of diacylglycerol ether (DAGE) (Fig. 2).

The large eggs of the 6 species with lecithotrophic development contained the same lipid classes as the eggs of the planktotrophs plus 2 additional components, wax (WE) and methyl ester (ME), in the triple development (Table S1, Fig. 1). Methyl ester was not present in the eggs of Ophionereis schayeri, Ophiocoma endeani and Ophiarthrum elegans. However, it was present in the eggs of Clarkcoma canaliculata, C. pulchra and Ophiarachnella ramsayi in small quantities (Table S1, Fig. 1). Wax ester was a minor lipid component in the eggs of Ophionereis schayeri but dominated the eggs of Ophiocoma endeani and

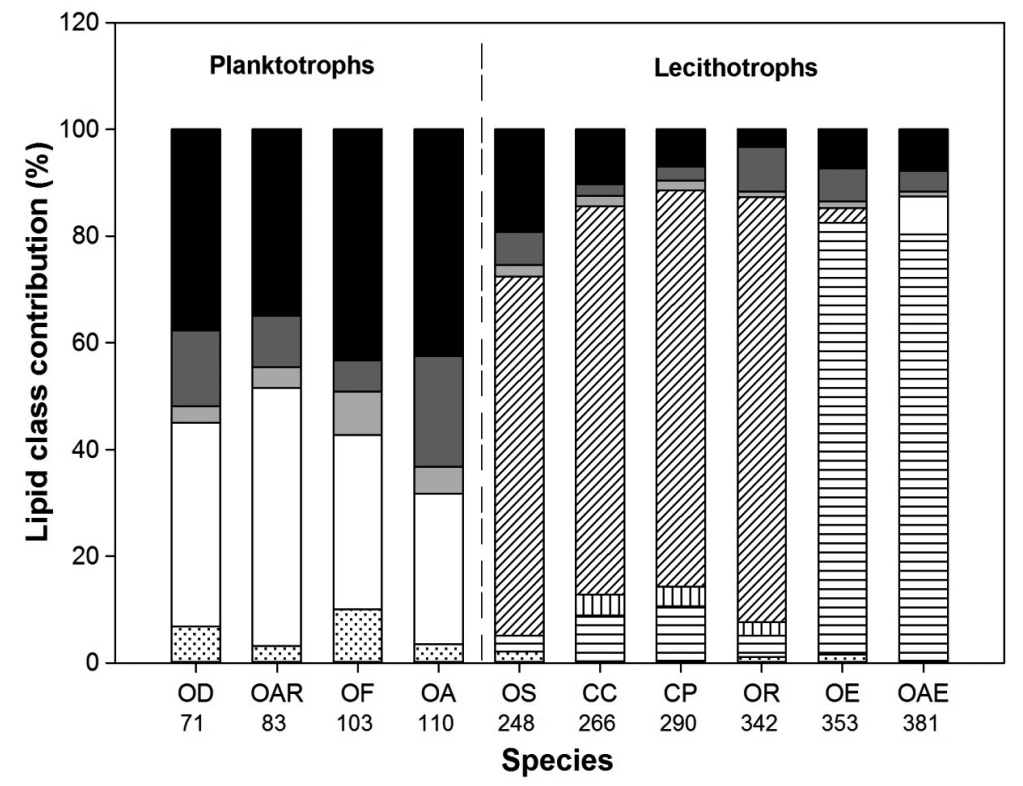

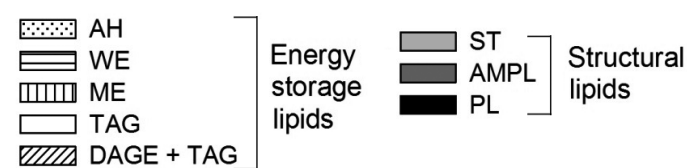

Fig. 1. Percentage of each lipid class in the eggs of 10 ophiuroid species from triple development data. This analysis does not separate DAGE and TAG and so was combined in the eggs of the lecithotrophic developers with the exception of Ophiarthrum elegans (OAE), which was not analysed for DAGE content. Individual lipid classes have been combined into energy storage lipids and structural lipids. Numbers below the species codes (see Table 1) represent mean egg diameters $(\mu \mathrm{m})$. Species are arranged according to egg size starting with the smallest on the left. Lipids - AH: aliphatic hydrocarbon; WE: wax ester; ME: methyl ester; TAG: triacylglycerol; DAGE: diacylglycerolether; ST: sterol; AMPL: acetone-mobile polar lipids; PL: phospholipid 

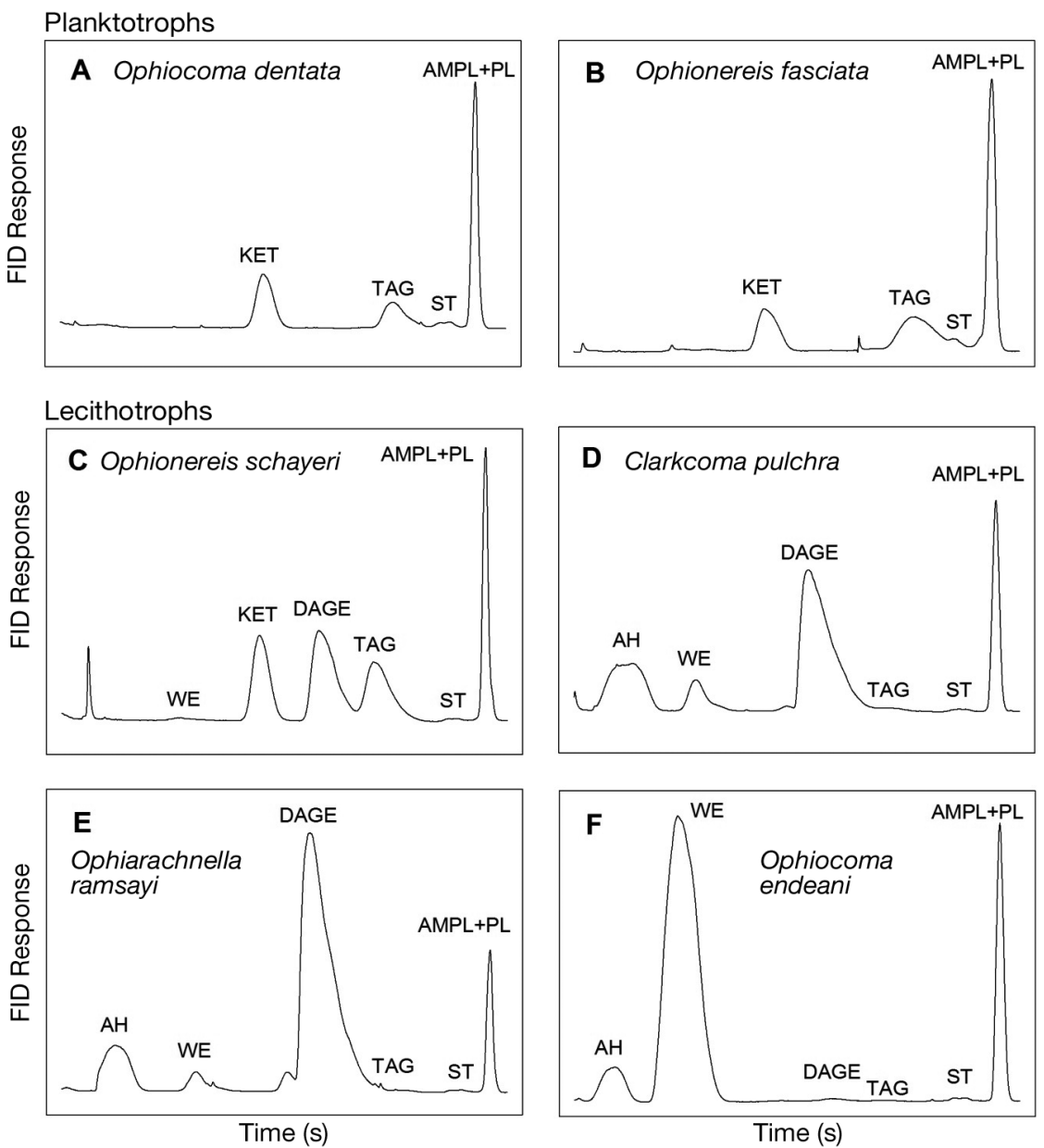

Fig. 2. Representative thin layer chromatography and flame ionization detection (TLC-FID) chromatograms of egg lipid extracts analysed using the 1-step development. (A,B) Egg lipid profiles of ophiuroids with planktotrophic development. (A) Ophiocoma dentata eggs contain TAG as the major energetic lipid; DAGE is not present. (B) Ophionereis fasciata eggs have a similar lipid profile to $O$. dentata. (C-F) Egg lipid profiles of ophiuroids with lecithotrophic development. (C) Ophionereis schayeri eggs contain similar amounts of DAGE and TAG and small amounts of WE. (D) In Clarkcoma pulchra eggs, DAGE is the main energetic lipid; WE and TAG are also present. (E) In Ophiarachnella ramsayi eggs DAGE is the main energetic lipid plus very small amounts of WE and TAG. (F) In contrast, Ophiocoma endeani eggs contain mostly WE as the single most important energetic lipid; and small amounts of DAGE and TAG. (A-C) Ketone (KET) internal standard; (D-F) aliphatic hydrocarbon (AH) internal standard. TAG: triacylglycerol; DAGE: diacylglycerol ether; WE: wax ester; ST: sterol; AMPL+PL: acetone-mobile polar lipids and phospholipids
Ophiarthrum elegans at about $80 \%$ of total lipid content. This lipid was also present in C. canaliculata, C. pulchra and Ophiarachnella ramsayi in varying amounts (4.0 to $10.2 \%$ of total lipid) (Table S1, Fig. 1).

The single-step non-polar development revealed that the TAG peak in the eggs of the lecithotrophic developers in the triple development was a combination of DAGE and TAG (Fig. 2). The amount of DAGE varied greatly among species (Table S3, Fig. 3). The eggs of Ophionereis schayeri and Ophiocoma endeani contained comparable amounts of DAGE and TAG, resulting in DAGE:TAG ratios of approximately 1:1 and 2:1, respectively (Table S3, Fig. 3). In contrast, DAGE dominated in the eggs of C. canaliculata, C. pulchra and Ophiarachnella ramsayi, with DAGE:TAG ratios ranging from 15:1 in C. canaliculata to 36:1 in O. ramsayi (Table S3, Fig. 3).

\section{Protein profiles}

In general, total protein increased with increasing egg size in all species, with the eggs of Ophiocoma dentata being the exception (Table S1, Fig. 4A). The mean protein concentration in the eggs of species with planktotrophic development was constant in the eggs of Ophiactis resiliens, Ophionereis fasciata and Ophiopteris antipodum (195.2 $\mathrm{ng} \mathrm{nl}^{-1}, 198.8 \mathrm{ng} \mathrm{nl}^{-1}$ and $190.7 \mathrm{ng} \mathrm{nl}^{-1}$, respectively) (Fig. 4B). The eggs of Ophiocoma dentata contained on average $20 \mathrm{ng}$ more protein per egg compared to those of Ophiactis resiliens, although $O$. dentata eggs are smaller than O. resiliens eggs (Table 1 , Table $\mathrm{S} 1$ ). This difference resulted in a significantly higher protein concentration in the eggs of $O$. dentata (385.3 $\mathrm{ng} \mathrm{nl}^{-1}$ ) compared to that in the eggs of the other small egg species (Fig. 4B) (nested ANOVA, $F_{3,7}=39.2, \mathrm{p}<0.01$ ). For the species with lecithotrophic development, protein increased with increasing egg size, ranging from $1086.9 \mathrm{ng} \mathrm{egg}^{-1}$ in Ophionereis schayeri to $4820.7 \mathrm{ng}$ $\mathrm{egg}^{-1}$ in Ophiarthrum elegans (Fig. 4A). Protein concentrations were significantly different between the eggs of planktotrophic and lecithotrophic developers, with the former having a higher protein concentration (Planned contrast, $t_{14}=9.79$, p $<0.0001$ ) (Fig. 4B). 


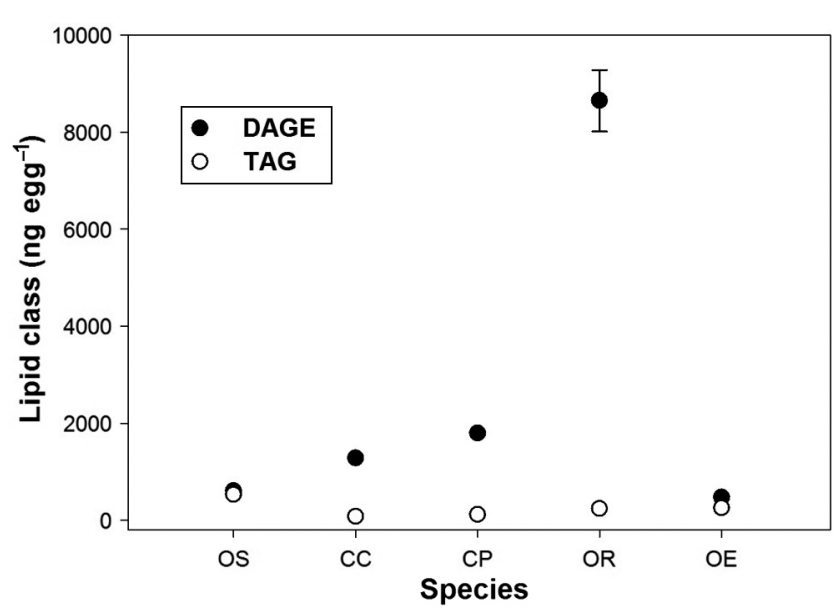

Fig. 3. Mean \pm SE DAGE and TAG content in the eggs of the ophiuroid species (for codes, see Table 1) with lecithotrophic development. Ophiarachnella ramsayi (OR) eggs contain $84 \%$ DAGE of the total lipid, while Ophiocoma endeani (OE) eggs, dominated by wax ester, contain $3 \%$ DAGE

\section{Maternal provisioning patterns in ophiuroids with planktotrophic and lecithotrophic development}

To compare egg lipid provisioning across the 10 ophiuroid species, the data were divided by egg volume and summarised in 2 categories: structural and energy storage lipids (Fig. 5). In the eggs of the planktotrophic species, energy storage lipids accounted for 32 to $52 \%$ of the total lipid content in the eggs compared to 72 to $89 \%$ in the eggs of the lecithotrophic species (Planned contrast, $t_{15}=44.3, \mathrm{p}<0.0001$ ) (Table S1 in the Supplement). Structural lipid concentrations were also significantly different in the 2 egg categories (Planned contrast, $t_{15}=5.8, \mathrm{p}<0.0001$ ), although differences were less pronounced than in energetic lipids (Fig. 5). Energy storage lipid concentrations increased with increasing egg volume (slope 11.446; Fig. 5). The increase in structural lipid concentration was minimal across all eggs (slope 0.23; Fig. 5).

The multivariate analyses (PERMANOVA and PERMDISP) of the lipid class and protein data standardised by egg volume indicated that egg composition of planktotrophic developers was significantly different from those of lecithotrophic developers (PERMANOVA, Pseudo- $F_{1,7}=3.12, \mathrm{p}($ perm $)=0.014$, Fig. 6). This analysis also indicated a significant difference in egg profiles between species of the same development mode (PERMANOVA, Pseudo- $F_{1,7}=$ $61.58, \mathrm{p}($ perm $)=0.0001$, Fig. 6). In the nMDS ordination, the eggs of the species with planktotrophic development (Ophiactis resiliens, Ophionereis fasciata and Ophiopteris antipodum) clustered in a dense
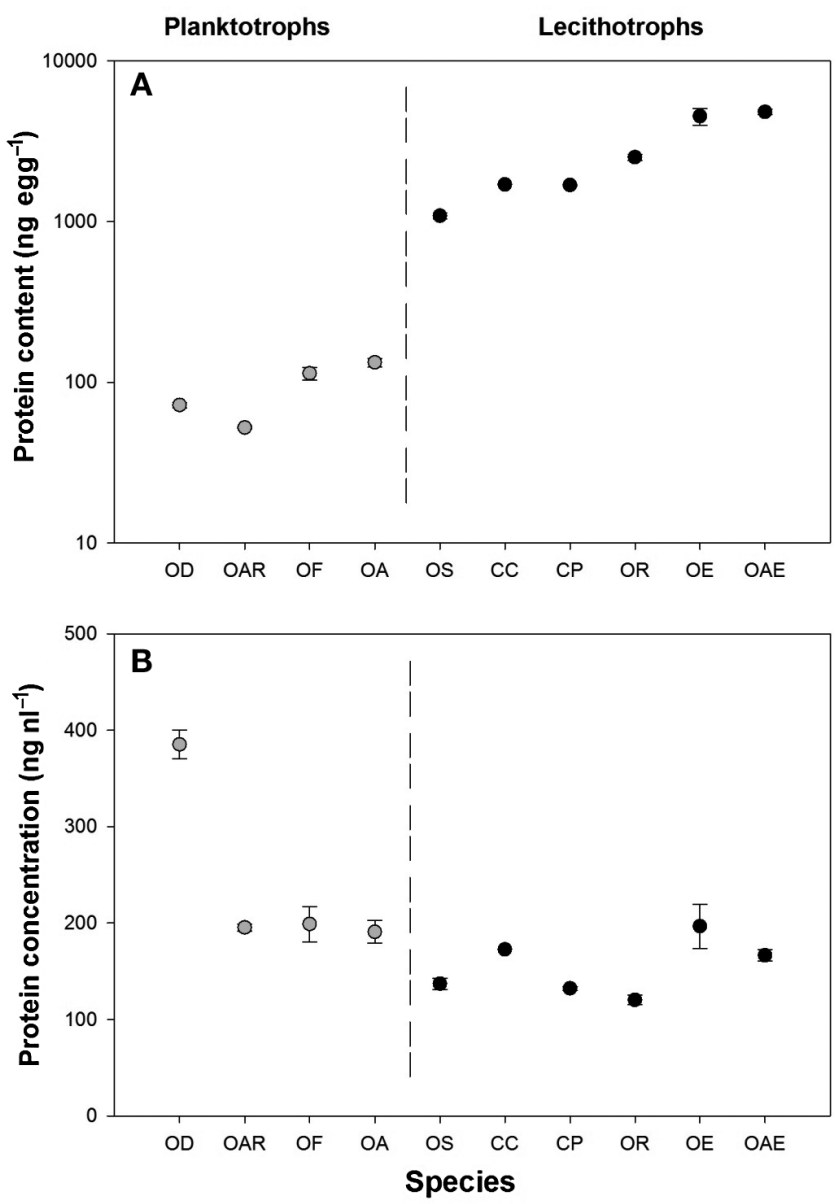

Fig. 4. Protein (A) content and (B) concentration $\pm \mathrm{SE}$ in the eggs of the ophiuroids (for species codes, see Table 1) with planktotrophic and lecithotrophic development. Protein content was divided by egg volume to obtain a protein concentration for a comparison independent of egg size. The protein content data are plotted on a $\log _{10}$ scale

group, indicating similar egg composition. Ophiocoma dentata was placed distant from these other small egg species, likely due to the considerably higher protein content of the eggs (Fig. 4B).

The eggs of the lecithotrophic developers Ophionereis schayeri and Clarkcoma pulchra $(<300 \mu \mathrm{m}$ diameter eggs) in the nMDS ordination were more similar to the eggs of the planktotrophic species than to those of the other lecithotrophic species Ophiocoma endeani and Ophiarthrum elegans (>300 $\mu \mathrm{m}$ diameter eggs) (Fig. 6). Ophiarachnella ramsayi, which has eggs $>300 \mu \mathrm{m}$ in diameter, grouped with Ophionereis schayeri and C. pulchra, indicating that the egg composition of these 3 species is more alike (Fig. 6). The second lipid analysis, however, showed that the eggs of Ophiarachnella ramsayi contain mostly DAGE and only a small amount of TAG, indicating that the large eggs of $O$. ramsayi are some- 


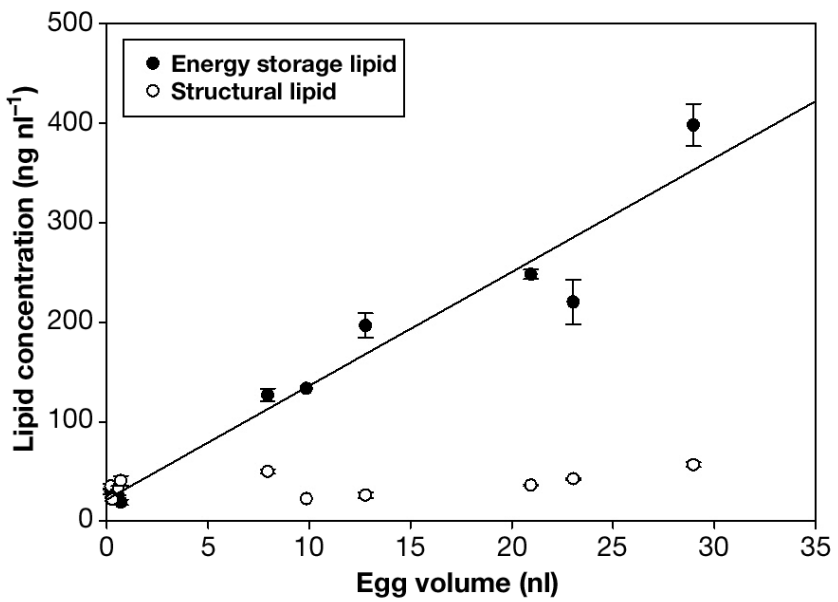

Fig. 5. Energy storage and structural lipid concentration \pm SE plotted against egg volume to show the relative contribution of each group to the total lipid concentration. Regression line $\left(F_{1,8}=141.127, \mathrm{p}<0.001\right)$ for energy storage lipids: $y=21.645+(11.446 \times$ egg volume $)$. Regression for structural lipids is non-significant $\left(F_{1,8}=2.681, \mathrm{p}=0.140\right)$

what less similar to the intermediate-size eggs of Ophionereis schayeri and C. pulchra than shown on the nMDS plot. Overall, the 4 species with lecithotrophic development were widely spread in multivariate space, indicating large differences in egg composition between the species (Fig. 6).

Permutational analysis of multivariate dispersions (PERMDISP) showed that dispersion of the biochemical data was significantly different between the 2 development modes (PERMDISP, $F_{1,22}=12.35, \mathrm{p}$

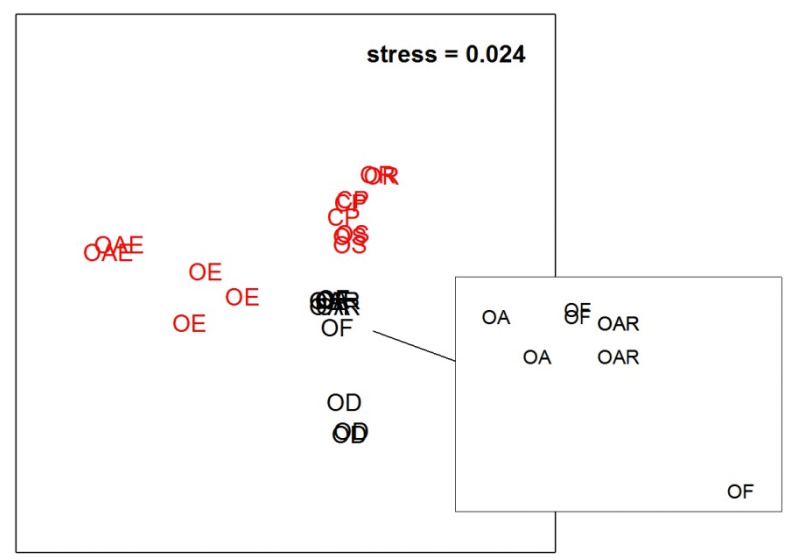

Fig. 6. Non-metric multi-dimensional scaling (nMDS) ordination showing differences in egg lipid composition of ophiuroids with planktotrophic (black) and lecithotrophic (red) development (for species codes, see Table 1). The eggs of planktotrophic developers have similar biochemistry with the exception of Ophiocoma dentata (OD). Eggs of lecithotrophic developers are considerably less similar in lipid and protein content, indicated by their disparate distribution in the plot
$($ perm $)=0.0166)$. The average distances to centroids for eggs of the planktotrophic and lecithotrophic developers were $75.97 \pm 13.34$ and $149.97 \pm 15.72$, respectively, indicating that the eggs of ophiuroids with lecithotrophic development are more different in lipid and protein composition.

\section{Comparison with maternal provisioning in other echinoderms}

Linear regression of the data generated here for the ophiuroids along with data previously determined for asteroids and echinoids is illustrated in Fig. 7. Overall, the relationship between the increase in lipid and protein content per egg and increasing egg
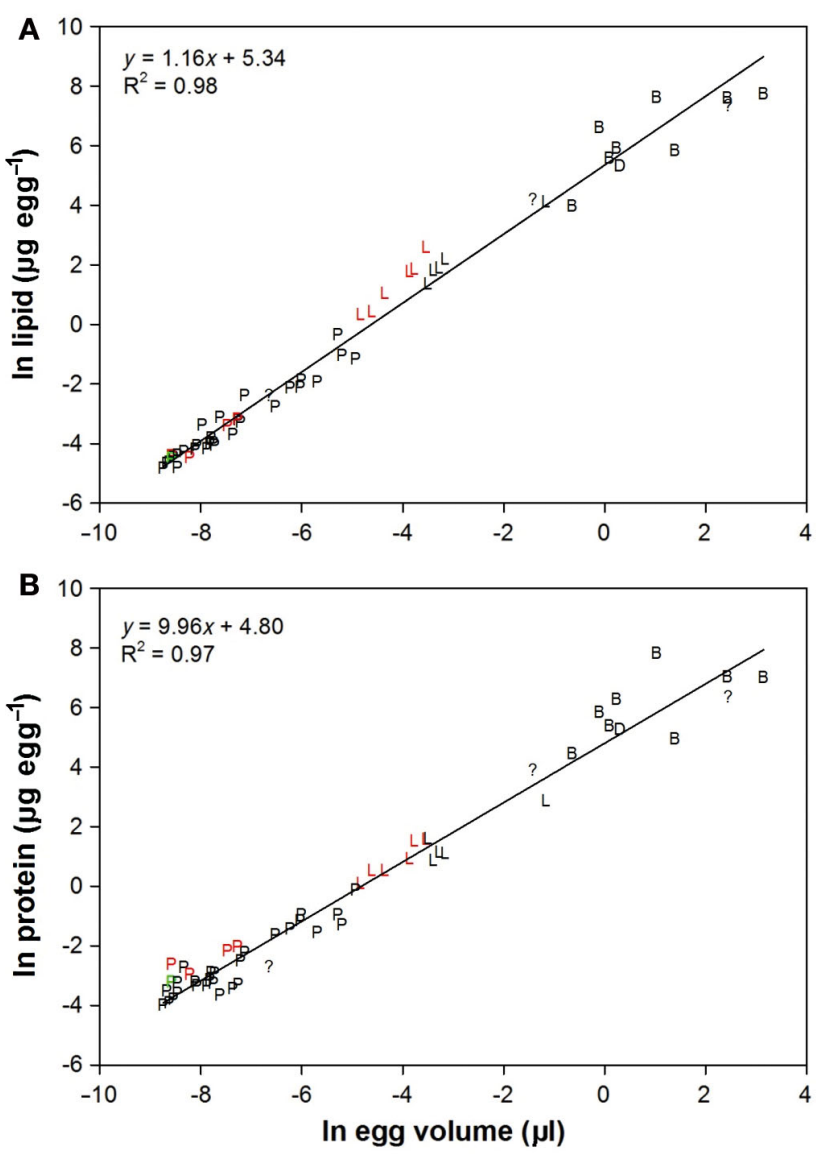

Fig. 7. (A) Lipid and (B) protein data of echinoderm eggs according to Sewell \& Manahan (2001) expanded with recent data from Prowse et al. (2008), McAlister \& Moran (2012, 2013), Whitehill \& Moran (2012) and this study. Previous data are entirely from asteroids and echinoids with the exception of Ophiocoma alexandri from Whitehill \& Moran (2012) (green symbol). Red symbols indicate ophiuroid data from this study, and black symbols indicate asteroid, echinoid and holothuroid data. P: planktotroph; L: lecithotroph;

D: direct; B: brooder; ?: unknown 
volume in ophiuroids is similar to that determined for echinoids and asteroids. In comparison to the eggs of other echinoderms with lecithotrophic development, the eggs of ophiuroids with this developmental mode are smaller and are placed in the gap between the data for the eggs of other echinoderms with planktotrophic and lecithotrophic development (largely echinoids and asteroids; see Table S2 in the Supplement).

\section{DISCUSSION}

\section{Eggs of ophiuroids with planktotrophic development}

The small eggs of ophiuroids with planktotrophic development were dominated by proteins, as is characteristic of this egg type in echinoderms (George et al. 1990, 1997, Jaeckle 1995, George 1999, Villinski et al. 2002, Moran et al. 2013). In general, the protein content of these eggs is 2- to 3-fold greater than the lipid content (Jaeckle 1995, George 1999). Across the 4 species with small eggs, protein content was particularly high in Ophiocoma dentata, as also indicated by egg protein histochemistry (Falkner et al. 2013). Similarly, elevated protein levels are reported in the eggs of another ophiocomid with planktotrophic development, O. alexandri (Whitehill \& Moran 2012).

The eggs of all species investigated contained 5 lipid classes: aliphatic hydrocarbon, triacylglycerol, sterol, acetone-mobile polar lipids and polar lipids. Triacylglycerol was the only energy storage lipid present in the small eggs of ophiuroids with planktotrophic development, although the relative amount of TAG differed substantially between species (range 28 to $48 \%$ of total lipid). The prevalence of TAG in the small eggs of ophiuroids and other echinoderms (Sewell 2005, Prowse et al. 2008, McAlister \& Moran 2012, 2013) suggests that this lipid class is the ancestral-type energy storage lipid. More data are needed, however, to determine if this pattern holds across taxonomically diverse echinoderms. Triacylglycerols are the most concentrated and prevalent form of energy storage in animals (Holmer 1989) and are prevalent in the ovaries and eggs of asteroids and echinoids (Kozhina et al. 1978, Oudejans \& van der Sluis 1979, Yasumasu et al. 1984, Broertjes et al. 1985, Liyana-Pathirana et al. 2002).

Overall, egg composition of the planktotrophs Ophionereis fasciata, Ophiactis resiliens and Ophiopteris antipodum were similar, as indicated by the nMDS plot. The multivariate analysis, however, showed that the small eggs of these species differed.
This difference may be attributed to the high protein content and comparatively high lipid content in the eggs of the only tropical planktotroph studied, Ophiocoma dentata (Falkner et al. 2013). Could the increased lipid and protein content in the eggs of this species be a response to a food-poor environment for the developing larvae? This hypothesis has been suggested in a comparative study of closely related planktotrophic echinoids from the western Atlantic and eastern Pacific (McAlister \& Moran 2012). The elevated protein levels in the eggs of Ophiocoma alexandri (Whitehill \& Moran 2012) indicate that this may also be a feature of small Ophiocoma eggs.

Whether the amount of structural and energy storage lipids and proteins in the small eggs of planktotrophic ophiuroids is 'just sufficient' to allow development to a functional feeding larval stage is not known. Previous studies in other echinoderms with planktotrophic development found that maternal investment is not minimised in the small eggs, although the resulting larvae are smaller and this size difference would have implications for larval success in nature (Sinervo \& McEdward 1988, Hart 1995, McEdward 1996, Allen 2012). Similarly, species of ophiuroids and other echinoderms that clone are capable of forming a new feeding larva from a fragment of a larval body that would have minimal energetic resources (Balser 1998), but the energetics of this process are not known.

\section{Maternal provisioning with a switch to lecithotrophy}

Life-history evolution in echinoderms has resulted in a shift from an ancestral state with a small egg and feeding larva to abbreviated development through a non-feeding larva (Strathmann 1985, 1993, Wray 1996, Raff \& Byrne 2006). Acquisition of a larger egg was an important step in the evolution of lecithotrophy, and this change is suggested to have been followed by the loss of the ability to feed (Wray 1996). The switch to non-feeding development in the ophiuroids investigated here was associated with the modification of egg composition. The large eggs of species with lecithotrophic development were significantly different in lipid and protein content compared with the ancestral-type small eggs. This pattern is also the case for asteroids (Prowse et al. 2008, 2009), indicating a similar change in evolution of maternal provisioning with a switch to lecithotrophy in ophiuroids and asteroids.

With regard to the focus of this study, the hypotheses that small and large eggs differ in lipid and pro- 
tein content was supported overall. However, there were marked differences evident within the maternal provisioning in the large egg category, supporting the hypothesis of the independent evolution of lecithotrophy multiple times within the Ophiuroidea. Overall, the transition to lecithotrophy in ophiuroids involved a switch in maternal provisioning strategy to provision with larger quantities of different energy storage lipids, namely WE and DAGE, in addition to the ancestral-type energy storage lipid TAG to produce an energy-dense egg. Ophiuroids therefore differ from echinoids and asteroids, where the evolution of non-feeding development has largely involved an increased oogenic deposition of DAGE only (Prowse et al. 2009). This is also the case for Heliocidaris erythrogramma (M. Byrne unpubl. data), correcting the previous report of wax esters in the eggs of this echinoid species with lecithotrophic development (Villinski et al. 2002).

\section{Eggs of ophiuroids with lecithotrophic development}

The large eggs of ophiuroids with lecithotrophic development were dominated by lipids, as is characteristic of echinoderms with this life history (Jaeckle 1995, Villinski et al. 2002, Prowse et al. 2009). In ophiuroids, the shift to a large egg is mainly associated with the increased deposition of energy storage lipids (lecithotrophs: 72 to $89 \%$ of total egg lipid vs. planktotrophs: 32 to $52 \%$ of total egg lipid). The composition of these lipids, however, differed significantly among species. The data indicated that the switch to lecithotrophy in ophiuroids was not due to simple upscaling of the ancestral TAG maternal provisioning strategy. In addition to TAG, several lipid classes (WE, ME and DAGE) were present in the large eggs of ophiuroids with lecithotrophic development. These data support our Hypothesis 3 of independent and multiple evolution of lecithotrophy within the Ophiuroidea resulting in different maternal provisioning strategies between species with large eggs.

It appears that egg size may have a major influence on egg composition in ophiuroids. The initial 3-step development indicated that the intermediate-sized eggs of Ophionereis schayeri, Clarkcoma pulchra and C. canaliculata and the eggs of Ophiarachnella ramsayi were dominated by TAG (83 to $92 \%$ of the total lipid content). However, subsequent 1-step analyses focusing on the TAG/DAGE content showed that the amount of TAG is, in fact, relatively consistent in the eggs of both planktotrophic and lecithotrophic species and that DAGE increases with in- creasing egg size. This result indicates that there may be a minimum amount of TAG (i.e. ng egg $^{-1}$ ) needed as short-term energy storage lipid required for development to the larval stage. It seems that the TAG content in the eggs of ophiuroids with lecithotrophic development may fuel construction of the larval body, while WE and DAGE may be stored as an energy reservoir for the early and post juvenile stage (Falkner 2007). Either DAGE (e.g. O. ramsayi) or WE (e.g. Ophiarthrum elegans and Ophiocoma endeani) were scaled-up in the larger eggs of these ophiuroids. These 2 lipid classes are considered longterm energy storage lipids (Lewis 1970, Sargent 1976, 1989, Prowse et al. 2009).

One could also argue that the evolution of lecithotrophic development in ophiuroids is a gradual process and that the maternal provisioning of Ophionereis schayeri, C. pulchra and C. canaliculata is less 'derived' than that of the larger eggs of species with lecithotrophic development. Ophiuroid eggs in the size seen for these 3 species (200 to $300 \mu \mathrm{m} \varnothing$ ) may approach the minimal amount of nutrients required to support development to the juvenile stage in the absence of feeding (Falkner et al. 2006). Thus, the eggs of O. schayeri, C. pulchra and C. canaliculata potentially represent the eggs of species in the transition to non-feeding development. This suggestion is supported by the presence of features in these larvae including reduced arm skeleton in armless larvae, a partial blind-ending larval mouth and ciliary bands - structures that have been interpreted as vestiges of ancestral-type ophioplutei (Selvakumaraswamy \& Byrne 2000a, 2004, Cisternas et al. 2004, Cisternas \& Byrne 2005). In contrast, the ophiuroids with largest eggs lack features associated with a feeding larva (skeleton and mouth). However, Hypothesis 4, that the small eggs of $O$. schayeri, $C$. pulchra and C. canaliculata would have a fundamentally different nutritive profile from the larger eggs of other lecithotrophic ophiuroids, is not supported. For crinoids, the components present in small eggs $(<250$ to $300 \mu \mathrm{m} \varnothing)$ are just enough to fuel development, resulting in a juvenile with low energy content, potentially reflecting selection to increase fecundity (McEdward et al. 1988). It would be interesting to compare the nutrient reserves of juvenile ophiuroids that develop from small and large eggs (e.g. Clarkoma spp. vs. Ophiarthrum spp.).

In addition to their energy value, lipids also provide buoyancy and help to conserve energy in pelagic organisms by assisting maintenance of position in the water column (Sargent \& Falk-Petersen 1988, Ackman 1989, Hagen \& Auel 2001), although 
lipids may also be an impediment to downward swimming (Emlet 1994). A positive correlation between egg lipid content and egg buoyancy has been reported for marine invertebrates (Arai et al. 1993, Villinski et al. 2002) and fishes (Riis-Vestergaard 2002). There has been a shift to increased buoyancy in eggs associated with the evolution of large, lipidrich eggs in most lecithotrophic echinoderms with planktonic larvae (Byrne \& Cerra 2000). The eggs of ophiuroids with eggs larger than $300 \mu \mathrm{m}$ in diameter, such as those of Ophiorachnella ramsayi, Ophiocoma endeani and Ophiarthrum elegans, are positively buoyant. WE and DAGE are inherently more buoyant than TAG due to a lower specific gravity (Lewis 1970). Sargent (1978) calculated that the same volume WE provides $70 \%$ more upthrust than TAG (WE $=0.188 \mathrm{~g} \mathrm{~g}^{-1}$ or $0.166 \mathrm{~g} \mathrm{ml}^{-1}$, TAG $=0.112 \mathrm{~g} \mathrm{~g}^{-1}$ or $0.106 \mathrm{~g} \mathrm{ml}^{-1}$ ). The eggs of the lecithotrophs Ophionereis schayeri, Clarkcoma canaliculata and C. pulchra, with diameters $<300 \mu \mathrm{m}$, were negatively buoyant. This result may partially be explained by their low WE and higher TAG content. Negatively buoyant eggs may be a feature of the lecithotrophic larvae of ophiuroids with comparatively small $(<300 \mu \mathrm{m} \varnothing)$ eggs in contrast to the highly buoyant larvae of the lecithotrophs with larger (>300 $\mu \mathrm{m} \varnothing)$ ) eggs (Table 1). This difference in egg lipids (DAGE vs. WE) may be a consequence of different diets or basic physiology. In vitro experiments have shown that asteroid ovaries are capable of de novo synthesis of lipids (Allen 1968). A similar mechanism may be involved with DAGE and WE synthesis in ophiuroids, resulting in a similar disparate distribution of these lipid classes in the eggs of the lecithotrophs. However, WE are abundant in coral reef systems, so the abundance of this lipid class in the eggs of the tropical species Ophiarthrum elegans and the subtropical species Ophiocoma endeani may have been influenced by diet (Lee \& Patton 1989, Arai et al. 1993).

\section{Ophiuroid eggs compared to other echinoderm eggs}

Few studies provide data on individual lipid class composition in echinoderm eggs (Villinski et al. 2002, Sewell 2005, Prowse et al. 2008, 2009, Moran et al. 2013). Other comparative studies determined total lipid but did not identify individual lipid classes (reviewed by Jaeckle 1995). Although the lipid and protein content in the ophiuroid eggs varied by several orders of magnitude among the 10 species investigated here, the overall trend was consistent with that documented for the eggs of other echinoderms.
Jaeckle's original graph on lipid and protein content versus egg volume, updated by Sewell \& Manahan (2001), shows a clear dichotomy between species with planktotrophic and lecithotrophic development, with data for these contrasting life-history modes plotted at 2 ends of the regression. A similar pattern was found for the ophiuroids investigated here, although the data were shifted to the left as a result of smaller egg sizes in species with lecithotrophic development. The data used for asteroids and echinoids include numerous brooders, with benthic eggs that are larger and more energy-rich than pelagic lecithotrophs (McEdward \& Morgan 2001). Egg lipid and protein data of asterinid sea stars with pelagic lecithotrophic development (Prowse et al. 2008) partially fill this gap. It is therefore questionable whether this dichotomy represents an existing pattern or is rather a consequence of sampling bias. The new data generated here for the intermediate egg sizes of ophiuroids with lecithotrophic development reflect the contents of eggs just slightly larger than those of asteroids and echinoids with planktotrophic development (200 to $300 \mu \mathrm{m} \varnothing$ ). In the regression of all echinoderm egg data, the lipid and protein data of these ophiuroid eggs were positioned between the 2 modes that characterise asteroid and echinoid eggs. This positioning indicates that maternal provisioning in these ophiuroids follows the same pattern typical for echinoderms with just a shift in size. Therefore, Hypothesis 4, that maternal provisioning in ophiuroids with lecithotrophic development, and which have comparatively small eggs (e.g. Ophionereis schayeri, Clarkoma pulchra and C. canaliculata) may be different from that of other echinoderms with lecithotrophic development is rejected. The eggs of O. schayeri, C. pulchra and C. canaliculata contained WE and DAGE in small amounts, lipid types that dominated the eggs of other lecithotrophic species with larger eggs.

It is interesting to note that the lipid concentration in the eggs of the ophiuroids with lecithotrophic development examined in this study increased with increasing egg size. This increase may represent an increase in energy storage lipid concentrations in these species beyond the level found in other echinoderms. Overall, however, among echinoderms, there appears to be a continuum in lipid and protein provisioning with increasing egg size. Data on the egg composition of holothuroids and crinoids are needed to provide a more complete picture of egg evolution in echinoderms. Determination of the nutritive profile in the eggs of echinoderm species with facultative planktotrophy is also likely to be particularly informative. 
Acknowledgements. The research was supported by a grant from the Australian Research Council (M.B.), the University of Auckland Research Fund (M.A.S.) and a University of Sydney International Postgraduate Research Scholarship (I.F.). We thank S. Bishop for assistance with the lipid analyses and E. Marzinelli and J. Harianto for assistance with the statistical analyses. The Bosch Institute provided facilities for protein analyses. Thanks to Dr. P. Nichols (CSIRO) and Dr. P. Virtue (UTas) for the DAGE standard. This is contribution number 147 of the Sydney Institute of Marine Science.

\section{LITERATURE CITED}

Ackman RG (1989) Marine biogenic lipids, fats, and oils. CRC Press, Boca Raton, FL

> Allen WV (1968) Fatty acid synthesis in the echinoderms: Asterias rubens, Echinus esculentus and Holothuria forskali. J Mar Biol Assoc UK 48:521-533

> Allen JD (2012) Effects of egg size reductions on development time and juvenile size in three species of echinoid echinoderms: implications for life history theory. J Exp Mar Biol Ecol 422-423:72-80

Allen JD, Pernet B (2007) Intermediate modes of larval development: bridging the gap between planktotrophy and lecithotrophy. Evol Dev 9:643-653

Allen JD, Podolsky RD (2007) Uncommon diversity in developmental mode and larval form in the genus Macrophiothrix (Echinodermata: Ophiuroidea). Mar Biol 151:85-97

Arai T, Kato M, Heyward A, Ikeda Y, Iizuka T, Maruyama T (1993) Lipid composition of positively buoyant eggs of reef building corals. Coral Reefs 12:71-75

Balser EJ (1998) Cloning by ophiuroid echinoderm larvae. Biol Bull 194:187-193

Broertjes JJS, De Waard P, Kamerling JP, Voogt PA (1985) Some characteristics of the non-protein moiety of vitellogenic substances in the starfish, Asterias rubens (L.). J Mar Biol Assoc UK 65:79-83

Byrne M (1991) Reproduction, development and population biology of the Caribbean ophiuroid Ophionereis olivacea, a protandric hermaphrodite that broods its young. Mar Biol 111:387-399

Byrne M, Cerra A (2000) Lipid dynamics in the embryos of Patiriella species (Asteroidea) with divergent modes of development. Dev Growth Differ 42:79-86

> Byrne M, Cerra A, Villinski JT (1999) Oogenic strategies in the evolution of development in Patiriella (Echinodermata: Asteroidea). Invertebr Reprod Dev 36:195-202

Byrne M, Sewell MA, Prowse TAA (2008) Nutritional ecology of sea urchin larvae: influence of endogenous and exogenous nutrition on echinopluteal growth and phenotypic plasticity in Tripneustes gratilla. Funct Ecol 22:643-648

> Cisternas P, Byrne M (2005) Evolution of abbreviated development in the ophiuroid Ophiarachnella gorgonia involves heterochronies and deletions. Can J Zool 83: 1067-1079

Cisternas P, Selvakumaraswamy P, Byrne M (2004) Evolution of development and the Ophiuroidea-revisited. In: Heinzeller T, Nebelsick JH (eds) Echinoderms: München. Taylor \& Francis, London, p 521-526

> Emlet RB (1986) Facultative planktotrophy in the tropical echinoid Clypeaster rosaceus and a comparison with obligate planktotrophy in Clypeaster subdepressus (Clypeasteroida: Echinoidea). J Exp Mar Biol Ecol 95:183-202

Emlet RB (1994) Body form and patterns of ciliation in non- feeding larvae of echinoderms: functional solutions to swimming in the plankton? Am Zool 34:570-585

Emlet RB, Hoegh-Guldberg O (1997) Effects of egg size on postlarval performance: experimental evidence from a sea urchin. Evolution 51:141-152

Emlet RB, McEdward LR, Strathmann RR (1987) Echinoderm larval ecology viewed from the egg. In: Jangoux $M$, Lawrence JM (eds) Echinoderm studies 2. Balkema, Rotterdam, p 55-136

Falkner I (2007) Evolution of maternal provisioning in ophiuroids: characterisation of egg nutrients and their roles in development. $\mathrm{PhD}$ dissertation, University of Sydney

Falkner I, Byrne M, Sewell MA (2006) Maternal provisioning in Ophionereis fasciata and O. schayeri: brittle stars with contrasting modes of development. Biol Bull 211: 204-207

Falkner I, Barbosa S, Byrne M (2013) Reproductive biology of four ophiocomid ophiuroids in tropical and temperate Australia-reproductive cycle and oogenic strategies in species with different modes of development. Invertebr Reprod Dev 57:189-199

> George SB (1999) Egg quality, larval growth and phenotypic plasticity in a forcipulate seastar. J Exp Mar Biol Ecol 237:203-224

George SB, Cellario C, Fenaux L (1990) Population differences in egg quality of Arbacia lixula (Echinodermata: Echinoidea): proximate composition of eggs and larval development. J Exp Mar Biol Ecol 141:107-118

George SB, Young CM, Fenaux L (1997) Proximate composition of eggs and larvae of the sand dollar Encope michelini (Agassiz): the advantage of higher investment in plankotrophic eggs. Invertebr Reprod Dev 32:11-19

> Hagen W, Auel H (2001) Seasonal adaptations and the role of lipids in oceanic zooplankton. Zoology 104:313-326

Hart MW (1995) What are the costs of small egg size for a marine invertebrate with feeding planktonic larvae? Am Nat 146:415-426

> Hart MW (1996) Evolutionary loss of larval feeding: development, form, and function in a facultatively feeding larva, Brisaster latifrons. Evolution 50:174-187

Holmer GK (1989) Triacylglycerols. In: Ackman RG (ed) Marine biogenic lipids, fats and oils. CRC Press, Boca Raton, FL, p 139-174

Jaeckle WB (1995) Variation in the size, energy content, and biochemical composition of invertebrate eggs: correlates to the mode of larval development. In: McEdward L (ed) Ecology of marine invertebrate larvae. CRC Press, Boca Raton, FL, p 49-77

Kozhina VP, Terekhova TA, Svetashev VI (1978) Lipid composition of gametes and embryos of the sea urchin Strongylocentrotus intermedius at early stages of development. Dev Biol 62:512-517

Lee RF, Patton JS (1989) Alcohol and waxes. In: Ackman RG (ed) Marine biogenic lipids, fats and oils. CRC Press, Boca Raton, FL, p 73-102

- Levitan DR (1993) The importance of sperm limitation to the evolution of egg size in marine invertebrates. Am Nat 141:517-536

Lewis RW (1970) The densities of three classes of marine lipids in relation to their possible role as hydrostatic agents. Lipids 5:151-153

Liyana-Pathirana C, Shahidi F, Whittick A (2002) The effect of an artificial diet on the biochemical composition of the gonads of the sea urchin (Strongylocentrotus droebachiensis). Food Chem 79:461-472 
McAlister JS, Moran AL (2012) Relationships among egg size, composition, and energy: a comparative study of geminate sea urchins. PLoS ONE 7:e41599

McAlister JS, Moran AL (2013) Effects of variation in egg energy and exogenous food on larval development in congeneric sea urchins. Mar Ecol Prog Ser 490:155-167

McEdward LR (1996) Experimental manipulation of parental investment in echinoid echinoderms. Am Zool 36:169-179

> McEdward LR, Miner BG (2001) Larval and life cycle patterns in echinoderms. Can J Zool 79:1125-1170

McEdward LR, Morgan KH (2001) Interspecific relationships between egg size and the level of parental investment per offspring in echinoderms. Biol Bull 200:33-50

> McEdward LR, Carson SF, Chia FS (1988) Energetic content of eggs, larvae, and juveniles of Florometra serrastissima and the implications for the evolution of crinoid life histories. Int J Inverterbr Reprod Dev 13:9-22

Moran AL, McAlister JS (2009) Egg size as a life history character of marine invertebrates: Is it all it's cracked up to be? Biol Bull 216:226-242

Moran AL, McAlister JS, Whitehill EAG (2013) Egg as energy: revisiting the scaling of egg size and energy content among echinoderms. Biol Bull 224:184-191

Oudejans RCHM, van der Sluis I (1979) Storage and depletion of lipid components in the pyloric caeca and ovaries of the seastar Asterias rubens during its annual reproductive cycle. Mar Biol 53:239-247

Parrish CC (1987) Separation of aquatic lipid classes by chromarod thin-layer chromatography with measurement by Iatroscan flame ionization detection. Can J Fish Aquat Sci 44:722-731

Parrish CC, Ackman RG (1983) Chromarod separations for the analysis of marine lipid classes by Iatroscan thin-layer chromatography-flame ionization detection. J Chromatogr A 262:103-112

Prowse TAA, Sewell MA, Byrne M (2008) Fuels for development: evolution of maternal provisioning in asterinid sea stars. Mar Biol 153:337-349

Prowse TAA, Falkner I, Sewell MA, Byrne M (2009) Longterm storage lipids and developmental evolution in echinoderms. Evol Ecol Res 11:1069-1083

Raff RA, Byrne M (2006) The active evolutionary lives of echinoderm larvae. Heredity 97:244-252

Riis-Vestergaard J (2002) Energy density of marine pelagic fish eggs. J Fish Biol 60:1511-1528

Sargent JR (1976) The structure, metabolism and function of lipids in marine organisms. In: Malins DC, Sargent JR (eds) Biochemical and biophysical perspectives in mar-

Editorial responsibility: James McClintock,

Birmingham, Alabama, USA ine biology, Vol 3. Academic Press, London, p 149-212

Sargent JR (1978) Marine wax esters. Sci Prog 65:437-458

Sargent JR (1989) Ether-linked glycerides in marine animals. In: Ackman RG (ed) Marine biogenic lipids, fats and oils. CRC Press, Boca Raton, FL, p 175-197

Sargent JR, Falk-Petersen S (1988) The lipid biochemistry of calanoid copepods. Hydrobiologia 167-168:101-114

Selvakumaraswamy P, Byrne M (2000a) Vestigial ophiopluteal structures in the lecithotrophic ophiuroid Ophioneries schayeri. Biol Bull 198:379-386

Selvakumaraswamy P, Byrne M (2000b) Reproduction, spawning, and development of 5 ophiuroids from Australia and New Zealand. Invertebr Biol 119:394-402

Selvakumaraswamy P, Byrne M (2004) Metamorphosis and developmental evolution in Ophionereis (Echinodermata: Ophiuroidea). Mar Biol 145:87-99

Sewell MA (2005) Utilization of lipids during early development of the sea urchin Evechinus chloroticus. Mar Ecol Prog Ser 304:133-142

Sewell MA, Manahan TD (2001) Echinoderm eggs: biochemistry and larval biology. In: Barker MF (ed) Echinoderms 2000. Swets \& Zeitlinger, Lisse, p 55-58

> Sewell MA, Young CM (1997) Are echinoderm egg size distributions bimodal? Biol Bull 193:297-305

> Sinervo B, McEdward LR (1988) Developmental consequences of an evolutionary change in egg size: an experimental test. Evolution 42:885-899

> Strathmann RR (1978) The evolution and loss of feeding larval stages of marine invertebrates. Evolution 32:894-906

> Strathmann RR (1985) Feeding and nonfeeding larval development and life-history evolution in marine invertebrates. Annu Rev Ecol Syst 16:339-361

Strathmann RR (1993) Hypotheses on the origins of marine larvae. Annu Rev Ecol Syst 24:89-117

> Thorson G (1950) Reproductive and larval ecology of marine bottom invertebrates. Biol Rev Camb Philos Soc 25:1-45

> Vance RR (1973) On reproductive strategies in marine benthic invertebrates. Am Nat 107:339-361

Villinski JT, Villinski JC, Byrne M, Raff RA (2002) Convergent maternal provisioning and life-history evolution in echinoderms. Evolution 56:1764-1775

> Whitehill EAG, Moran AL (2012) Comparative larval energetics of an ophiuroid and an echinoid echinoderm. Invertebr Biol 131:345-354

> Wray GA (1996) Parallel evolution of nonfeeding larvae in echinoids. Syst Biol 45:308-322

Yasumasu I, Hino A, Suzuki A, Mita M (1984) Change in the triacylglycerol level in sea urchin eggs and embryos during early development. Dev Growth Differ 26:525-532

Submitted: September 22, 2014; Accepted: January 22, 2015 Proofs received from author(s): April 1, 2015 